\title{
IbM Pelatihan Pembuatan Paket Wisata Tematik Sejarah, Pelayanan Prima dan Tour Guide Bagi Pengelola Wisata
}

\author{
Fauzan Putraga Al-Bahri, Ihsanuddin, Jhony Syafwandhinata \\ Program Studi Manajemen Informatika, Fakultas Ilmu Komputer, \\ AMIK Indonesia, Jl. T Nyak Arief Sp Mesra No. 400, Kota Banda Aceh, Indonesia \\ Email: fauzanputragaalbahri@amikindonesia.ac.id
}

\begin{abstract}
Abstrak
Tujuan dari kegiatan ini adalah untuk meningkatkan kemampuan pengelola dan warga Kampung Wisata Iboih Kota Sabang tentang bagaimana mengelola sebuah destinasi wisata. Hai ini penting mengingat per 24 Januari 2016 Kampung Wisata Iboih Kota Sabang telah resmi ditetapkan sebagai Destinasi Unggulan di Kota Sabang. Oleh karena itu, pengelola dan warga sangat memerlukan pengetahuan dan ketrampilan mengenai penglolaan kampong wisata yang meliputi: Pelatihan Manajemen Destinasi Wisata, Pembuatan Paket Wisata Tematik Sejarah, Pelayanan prima dan Tour Guide. Setelah pelatihan, diharapkan mereka paham dan memiliki pengetahuan mengenai aspek-aspek dalam pengelolaan sebuah destinasi. Kehadiran wisatawan di Kota Sabang, baik wisatawan domestik maupun wisatawan mancanegara sangat diharapkan oleh pariwisata Kota Sabang. Oleh karena itu bagaimana 'menahan' wisatawan agar mau tinggal lebih lama dan mengeksplorasi wisata Kota Sabang sangat penting dilakukan. Untuk itu kuncinya adalah terletak pada pengelolaan destinasi wisata yang tepat. Seiring peningkatan kemampuan pengelola dan warga tersebut, diharapkan pelaku jasa wisata setempat semakin profesional yang pada akhirnya dapat juga meningkatkan kepuasan wisatawan/pengunjung. Lebih penting lagi, keberadaan Kampung Iboih menjadi semakin stabil dan unggul dalam peta destinasi wisata Kota Sabang.
\end{abstract}

Kata Kunci: IbM, Pelatihan, Paket Wisata, Tour Guide, Pengelola Wisata.

\section{Pendahuluan}

Pariwisata di Indonesia merupakan industri yang berkembang pesat. Menurut Biro Statistik Indonesia [1], jumlah kedatangan wisatawan internasional telah meningkat sebesar 9.24 persen pada 2011 [2]. Jumlah wisatawan internasional yang datang ke Indonesia selama tiga tahun antara tahun 2009 dan 2011 adalah 6.323 juta [3], 7.002 juta dan 7.649 juta [4]. Secara keseluruhan, pada tahun 2011, perekonomian usaha perjalanan dan pariwisata Indonesia menghasilkan Rp 640,798 miliar. Angka ini memberikan kontribusi sekitar 8,8 persen dari PDB Indonesia tahun 2011, dengan 2,6 persen dari seluruh tenaga kerja Indonesia terlibat dalam pekerjaan wisata. Selain itu, angka tersebut juga menghasilkan 8,7 persen pendapatan ekspor total [5]. Pertumbuhan pariwisata merupakan generator keempat negara devisa setelah minyak/gas, kelapa sawit dan lateks [6].

Destiansi wisata yang baik harus mendatangkan wisatawan sebanyak-banyaknya [7], menahan mereka dalam waktu yang cukup lama dan memberi kepuasan pada wisatawan yang datang berkunjung [8]. Selain itu peningkatan skill pelayanan wisata juga diperlukan [9]. Pelayanan merupakan suatu proses dimana proses tersebut menghasilkan suatu produk yang berupa pelayanan kemudian diberikan kepada pelanggan $[10,11,12]$. Standar pelayanan merupakan ukuran yang telah ditentukan sebagai suatu pembakuan pelayanan yang baik. Standar pelayanan mengandung baku mutu pelayanan $[13,14]$.

Pelayanan prima merupakan terjemahan istilah "excellent service" yang secara harfiah berarti pelayanan terbaik atau sangat baik [15]. Disebut sangat baik atau terbaik karena sesuai dengan standar pelayanan yang berlaku atau dimiliki instansi pemberi pelayanan [16]. Hakekat pelayanan publik adalah pemberian pelayanan prima kepada masyarakat yang merupakan perwujudan 
kewajiban aparatur pemerintah sebagai abdi masyarakat [17]. Agenda perilaku pelayanan sektor publik pelayanan prima adalah:

a. Pelayanan yang terbaik dari pemerintah kepada pelanggan atau pengguna jasa.

b. Pelayanan prima ada bila ada standar pelayanan.

c. Pelayanan prima bila melebihi standar atau sama dengan standar.

d. Pelanggan adalah masyarakat luas; masyarakat eksternal dan internal $[17,16]$.

Pelayanan umum dapat diartikan memproses pelayanan kepada masyarakat atau customer, baik berupa barang atau jasa melalui tahapan, prosedur [18], persyaratan-persyaratan, waktu dan pembiayaan yang dilakukan secara transparan untuk mencapai kepuasan sebagaimana visi yang telah ditetapkan dalam organisasi [19]. Pelayanan Prima sebagaimana tuntutan pelayanan yang memuaskan pelanggan/masyarakat memerlukan persyaratan bahwa setiap pemberi layanan yang memiliki kualitas kompetensi yang professional [20], dengan demikian kualitas kompetensi profesionalisme menjadi sesuatu aspek penting dan wajar dalam setiap transaksi [21].

Diharapkan dengan adanya pelatihan tersebut perlu dilakukan agar para pelaku wisata di Kota Sabang secara khusus dapat menumbuhkan dan meningkatkan kemampuan memberikan layanan jasa wisata yang baik sesuai harapan wisatawan yang berkunjung ke Kota Sabang. Seiring peningkatan kemampuan layanan prima tersebut diharapkan pelaku jasa wisata setempat semakin profesional yang pada akhirnya dapat juga meningkatkan kepuasan pengunjung.

\subsection{Tujuan Kegiatan}

Tujuan kegiatan PPM ini adalah meningkatkan pengetahuan dan pemahaman bagi Pengelola Kampung Wisata Iboih, Pengelola Koperasi Kampung Wisata Iboih, dan Warga Kampung Wisata Iboih terhadap pengelolaan wisata sehingga terciptanya kunjungan yang meningkatkan ekonomi masyarakat lokal.

\subsection{Manfaat Kegiatan}

Manfaat kegiatan ini adalah

a. Peningkatan pengetahuan Manajemen Kampung Wisata

b. Peningkatan skill dan kemampuan akan Manajemen Kampung Wisata

c. Peningkatan pengetahuan bagaimana membuat paket wisata tematik sejarah

d. Peningkatan skill dan kemampuan bagaimana membuat paket wisata tematik sejarah

e. Peningkatan pengetahuan bagaimana meng-guide dan melayani wisatawan

f. Peningkatan skill dan kemampuan bagaimana meng-guide dan melayani wisatawan.

\section{Realisasi Kegiatan}

\subsection{Bentuk Kegiatan \& Jadwal, Serta Tempat Kegiatan \\ a. Metode Pelaksanaan Kegiatan}

Kegiatan pengabdian kepada masyarakat ini dilakukan dengan beberapa metode mulai dari Ceramah, Diskusi, Praktek, Pembuatan Modul, Role play dan Evaluasi.

\section{b. Waktu Efektif Pelaksanaan Kegiatan}

Kegiatan Pelaksanaan Pengabdian Kepada Masyarakat ini dilakukan secara bertahap; yakni: 3 Juni 2016, 24 Juni 2016 dan 8 Juli 2016:

Tabel 1. Jadwal Pelaksanaan

\begin{tabular}{|c|l|c|c|c|}
\hline \multirow{2}{*}{ NO } & \multicolumn{1}{|c|}{ Kegiatan } & \multicolumn{3}{|c|}{ Jadwal Pelaksanaan Tanggal } \\
\cline { 3 - 4 } & & 3 Juni & 24 Juni & 8 Juli \\
\hline 1 & Persiapan & & & \\
\hline 2 & Praktikum Pelatihan dan Pembinaan & & & \\
\hline 3 & Penutupan & & & \\
\hline
\end{tabular}




\section{c. Tempat Kegiatan}

Lokasi pengabdian ini pada daerah Desa Iboih Kecamatan Sukakarya Kota Sabang. Gampong Iboih merupakan gampong dengan daerah terluas yang ada di Kecamatan Sukakarya, yaitu dengan luas daerah 18,25 km2 atau 25\% dari $73 \mathrm{~km} 2$ yang merupakan luas daerah Kecamatan Sukakarya. Gampong Iboih juga memiliki tiga jurong dengan luas sebesar $25 \mathrm{~km}$.

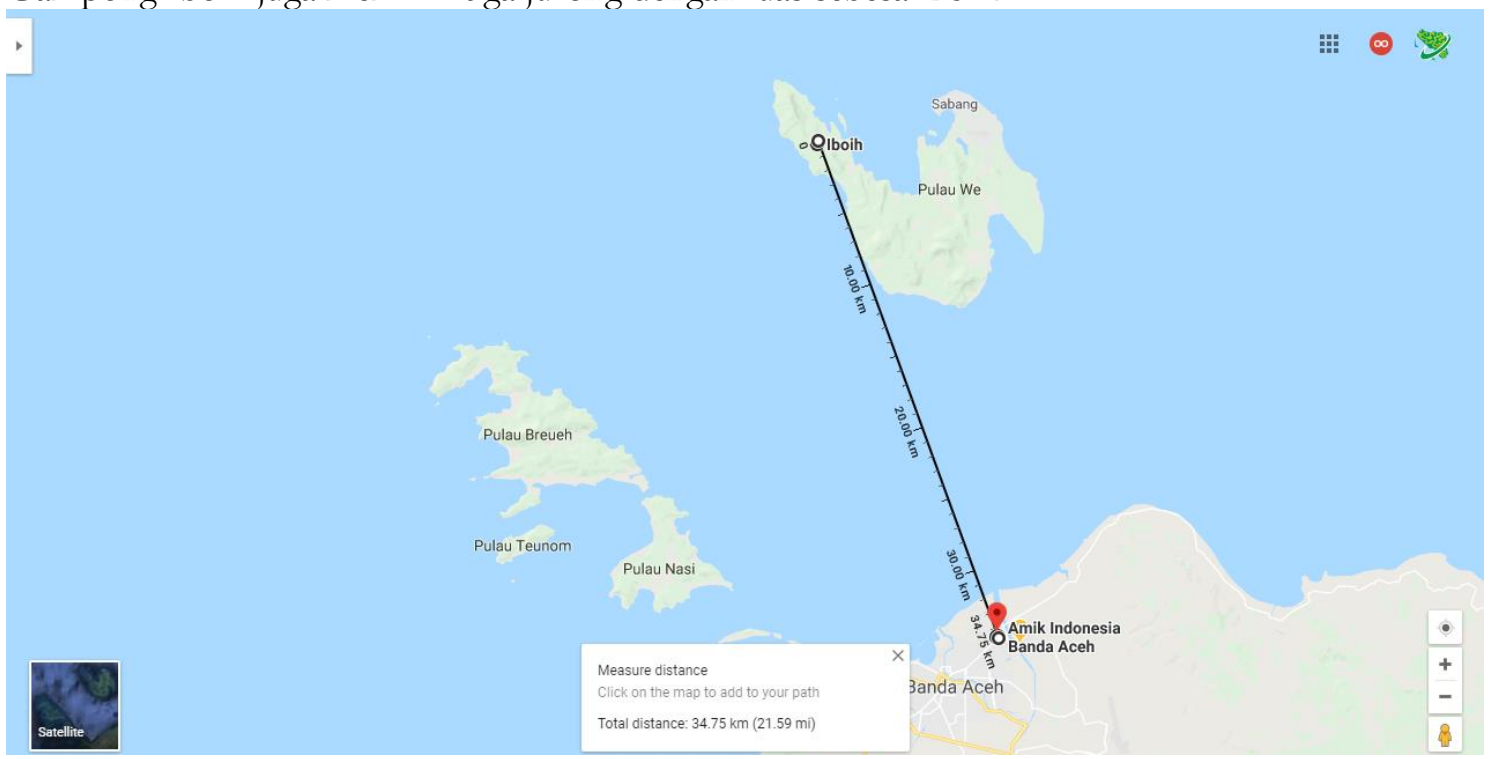

Gambar 1. Map Lokasi Kegiatan
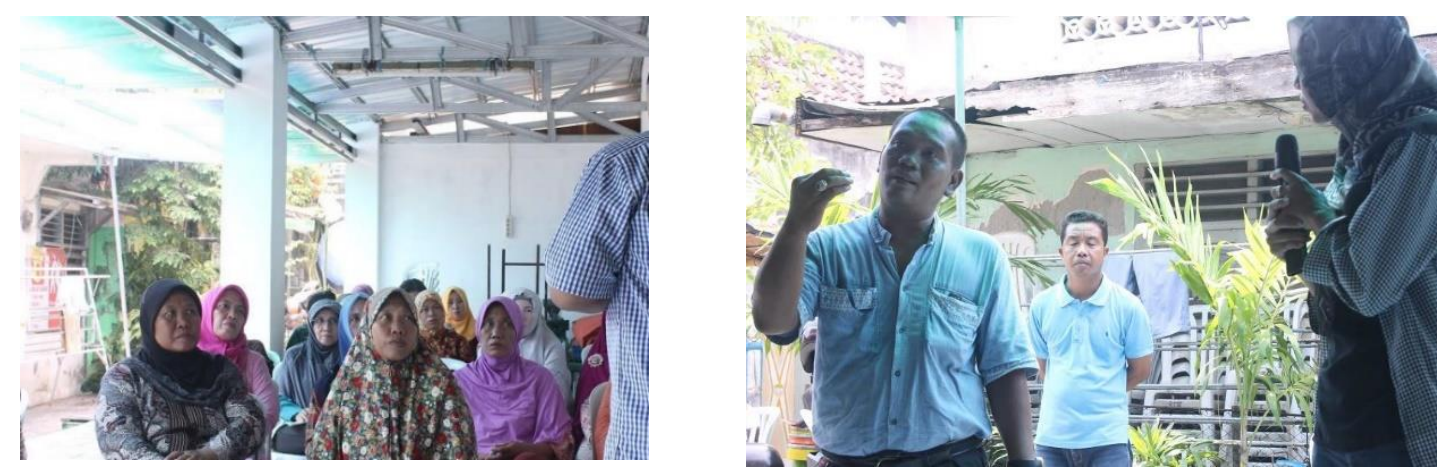

Gambar 2. Kegiatan Pengabdian

\subsection{Hasil Pelaksanaan Pengabdian}

Jadwal acara yang dilakukan untuk kegiatan pengabdian masyarakat adalah sebagai berikut

Tabel 2. Materi Sosialisasi

\begin{tabular}{|c|l|c|}
\hline Pokok Bahasan & \multicolumn{1}{|c|}{ Sub Pokok Bahasan } & Diadakan Tanggal \\
\hline $\begin{array}{c}\text { Manajemen } \\
\text { Destinasi Wisata }\end{array}$ & $\begin{array}{l}\text { Pengantar Pariwisata } \\
\text { Pemahaman tentang pengelolaan atraksi } \\
\text { wisata yang baik }\end{array}$ & 3 Juni 2016 \\
\hline & $\begin{array}{l}\text { Pemahaman tentang pengelolaan destinasi } \\
\text { wisata }\end{array}$ & 3 Juni 2016 \\
\hline & Bagaimana mengelola koperasi wisata & 24 Juni 2016 \\
\hline
\end{tabular}


Jurnal Pengabdian Nasional (JPN) Indonesia

Vol 1 No 1, Januari-Juni (2020)

\begin{tabular}{|c|c|c|}
\hline $\begin{array}{l}\text { Pembuatan } \\
\text { Produk } \\
\text { Paket Wisata }\end{array}$ & $\begin{array}{l}\text { Langkah-langkah operasional } \\
\text { perencanaan produk wisata } \\
\text { Penghitungan Harga } \\
\text { Praktek }\end{array}$ & 24 Juni 2016 \\
\hline & Praktek Penghitungan Harga Paket & 24 Juni 2016 \\
\hline & Praktek Membuat Paket & 24 Juni 2016 \\
\hline \multirow[t]{2}{*}{$\begin{array}{l}\text { Pelatihan Tour } \\
\text { Guide }\end{array}$} & $\begin{array}{l}\text { Pelatihan bagaimana meng-guide } \\
\text { wisatawan } \\
\text { Pembekalan metode guiding yang tepat }\end{array}$ & 8 Juli 2016 \\
\hline & $\begin{array}{l}\text { Pelatihan bagaimana meng-guide } \\
\text { wisatawan } \\
\text { Pembekalan metode guiding yang tepat }\end{array}$ & 8 Juli 2016 \\
\hline $\begin{array}{l}\text { Service Excellence } \\
\text { (Pelayanan Prima) }\end{array}$ & & 8 Juli 2016 \\
\hline $\begin{array}{l}\text { Pengertian dasar } \\
\text { Etika pelayanan }\end{array}$ & $\begin{array}{l}\text { Pengertian Etika } \\
\text { Pengertian pelayanan } \\
\text { Unsur-unsur pelayanan } \\
\text { Dimensi-dimensi pelayanan } \\
\text { Keterkaitan antara pelayanan dan } \\
\text { industri jasa (Perhotelan) } \\
\text { Tujuan pelayanan } \\
\text { Kegunaan mempelajari Etika } \\
\text { pelavanan }\end{array}$ & 8 Juli 2016 \\
\hline $\begin{array}{l}\text { Kepribadian } \\
\text { sebagai penunjang } \\
\text { pelayanan }\end{array}$ & $\begin{array}{l}\text { Pengertian kepribadian } \\
\text { Unsur-unsur kepribadian } \\
\text { Teori kepribadian }\end{array}$ & 8 Juli 2016 \\
\hline $\begin{array}{l}\text { Kepribadian } \\
\text { petugas pelayanan }\end{array}$ & Kepribadian petugas pelayanan & 8 Juli 2016 \\
\hline $\begin{array}{l}\text { memahami } \\
\text { Psikologi } \\
\text { konsumen }\end{array}$ & $\begin{array}{l}\text { Pengertian dasar psikologi } \\
\text { konsumen } \\
\text { Menjual sebagai bentuk pelayanan } \\
\text { Motivasi orang membeli Karakteristik } \\
\text { konsumen } \\
\text { Mengukur kepuasan Konsumen }\end{array}$ & 8 Juli 2016 \\
\hline $\begin{array}{l}\text { Etiket Berpakaian } \\
\text { dan Berpenampilan } \\
\text { dalam bekerja }\end{array}$ & $\begin{array}{l}\text { Pentingnya penampilan dalam } \\
\text { bekerja } \\
\text { Fungsi penampilan } \\
\text { Penggunaan seragam dalam } \\
\text { pelayanan } \\
\text { Etiket berbusana dalam menunjang } \\
\text { pelayanan }\end{array}$ & 8 Juli 2016 \\
\hline Pelayanan Prima & $\begin{array}{l}\text { Pengertian pelayanan Prima } \\
\text { Perilaku melayani }\end{array}$ & 8 Juli 2016 \\
\hline $\begin{array}{l}\text { Komunikasi dalam } \\
\text { Pelayanan }\end{array}$ & $\begin{array}{l}\text { Pengertian Komunikasi } \\
\text { Unsur-unsur dalam komunikasi } \\
\text { Hambatan komunikasi Komunikasi } \\
\text { \& Pelayanan }\end{array}$ & 8 Juli 2016 \\
\hline
\end{tabular}


Jurnal Pengabdian Nasional (JPN) Indonesia

Vol 1 No 1, Januari-Juni (2020)

E-ISSN: 2723-7060

\begin{tabular}{|c|c|c|}
\hline \multirow[t]{3}{*}{$\begin{array}{c}\text { Manajemen } \\
\text { Destinasi Wisata }\end{array}$} & $\begin{array}{l}\text { Pengantar Pariwisata } \\
\text { Pemahaman tentang pengelolaan atraksi } \\
\text { wisata yang baik }\end{array}$ & 3 Juni 2016 \\
\hline & $\begin{array}{l}\text { Pemahaman tentang pengelolaan destinasi } \\
\text { wisata }\end{array}$ & 3 Juni 2016 \\
\hline & Bagaimana mengelola koperasi wisata & 24 Juni 2016 \\
\hline \multirow[t]{3}{*}{$\begin{array}{l}\text { Pembuatan } \\
\text { Produk } \\
\text { Paket Wisata }\end{array}$} & $\begin{array}{l}\text { Langkah-langkah operasional } \\
\text { perencanaan produk wisata } \\
\text { Penghitungan Harga } \\
\text { Praktek }\end{array}$ & 24 Juni 2016 \\
\hline & Praktek Penghitungan Harga Paket & 24 Juni 2016 \\
\hline & Praktek Membuat Paket & 24 Juni 2016 \\
\hline \multirow[t]{2}{*}{$\begin{array}{l}\text { Pelatihan Tour } \\
\text { Guide }\end{array}$} & $\begin{array}{l}\text { Pelatihan bagaimana meng-guide } \\
\text { wisatawan } \\
\text { Pembekalan metode guiding yang tepat }\end{array}$ & 8 Juli 2016 \\
\hline & $\begin{array}{l}\text { Pelatihan bagaimana meng-guide } \\
\text { wisatawan } \\
\text { Pembekalan metode guiding yang tepat }\end{array}$ & 8 Juli 2016 \\
\hline $\begin{array}{l}\text { Service Excellence } \\
\text { (Pelayanan Prima) }\end{array}$ & & 8 Juli 2016 \\
\hline $\begin{array}{l}\text { Pengertian dasar } \\
\text { Etika pelayanan }\end{array}$ & $\begin{array}{l}\text { Pengertian Etika } \\
\text { Pengertian pelayanan } \\
\text { Unsur-unsur pelayanan } \\
\text { Dimensi-dimensi pelayanan } \\
\text { Keterkaitan antara pelayanan dan } \\
\text { industri jasa (Perhotelan) } \\
\text { Tujuan pelayanan } \\
\text { Kegunaan mempelajari Etika } \\
\text { pelavanan }\end{array}$ & 8 Juli 2016 \\
\hline $\begin{array}{l}\text { Kepribadian } \\
\text { sebagai penunjang } \\
\text { pelayanan }\end{array}$ & $\begin{array}{l}\text { Pengertian kepribadian } \\
\text { Unsur-unsur kepribadian } \\
\text { Teori kepribadian }\end{array}$ & 8 Juli 2016 \\
\hline $\begin{array}{l}\text { Kepribadian } \\
\text { petugas pelayanan }\end{array}$ & Kepribadian petugas pelayanan & 8 Juli 2016 \\
\hline $\begin{array}{l}\text { memahami } \\
\text { Psikologi } \\
\text { konsumen }\end{array}$ & $\begin{array}{l}\text { Pengertian dasar psikologi } \\
\text { konsumen } \\
\text { Menjual sebagai bentuk pelayanan } \\
\text { Motivasi orang membeli Karakteristik } \\
\text { konsumen } \\
\text { Mengukur kepuasan Konsumen }\end{array}$ & 8 Juli 2016 \\
\hline
\end{tabular}




\begin{tabular}{|c|c|c|}
\hline $\begin{array}{l}\text { Etiket Berpakaian } \\
\text { dan Berpenampilan } \\
\text { dalam bekerja }\end{array}$ & $\begin{array}{ll}\text { - } & \text { Pentingnya penampilan dalam } \\
\text { - } & \text { Fungsia penampilan } \\
\text { - } & \text { Penggunaan seragam dalam } \\
\text { - } & \text { pelayanan } \\
\text { - } & \text { Etiket berbusana dalam menunjang } \\
& \text { pelayanan }\end{array}$ & 8 Juli 2016 \\
\hline Pelayanan Prima & $\begin{array}{l}\text { Pengertian pelayanan Prima } \\
\text { Perilaku melayani }\end{array}$ & 8 Juli 2016 \\
\hline $\begin{array}{l}\text { Komunikasi dalam } \\
\text { Pelayanan }\end{array}$ & $\begin{array}{ll}\text { - } & \text { Pengertian Komunikasi } \\
\text { - } & \text { Unsur-unsur dalam komunikasi } \\
\text { - Hambatan komunikasi Komunikasi } \\
\text { - } \quad \text { \& Pelayanan }\end{array}$ & 8 Juli 2016 \\
\hline
\end{tabular}

Tabel 3. Daftar Kegiatan

\begin{tabular}{|c|c|c|c|}
\hline No & Waktu & Kegiatan & Penanggungjawab \\
\hline 1 & $08.00-09.00$ & Persiapan peserta & Panitia \\
\hline 2 & $09.00-09.30$ & $\begin{array}{l}\text { Pembukaan } \\
\text { 1. Menyanyikan lagu } \\
\text { Indonesia Raya } \\
\text { 2. Sambutan } \\
\text { Ketua Panitia } \\
\text { 3. Sambutan Mitra }\end{array}$ & Moderator \\
\hline & $09.30-10.00$ & Pemaparan materi Sesi I & Panitia \\
\hline 3 & $10.00-10.15$ & Istirahat/break & \\
\hline 4 & $10.15-11.30$ & Pemaparan materi Sesi II & Panitia \\
\hline 5 & $11.30-12.00$ & Tanya Jawab & Moderator \\
\hline 6 & $13.00-14.00$ & Pemaparan materi Sesi III & Panitia \\
\hline 7 & $14.00-14.15$ & Tanya Jawab & Moderator \\
\hline 8 & 14.15 & Penutupan & \\
\hline
\end{tabular}

Pelaksanaan kegiatan dilakukan secara bertahap yaitu pada tanggal 3 Juni 2016, 24 Juni 2016 dan 8 Juli 2016. Beberapa kali pertemuan informal mengenai materi pelatihan digelar oleh tim dan pengurus Kampung Iboih juga digelar. Bagaimana pengelolaan koperasai wisata yang baik juga disampaikan dalam kegiatan kunjungan informal ini. Dalam beberapa kali kunjungan informal ini juga dilakukan pemaparan dan penyampaian materi kepada pengurus dan tokoh masyarakat. Kegiatan informal ini juga membuat keakraban terasa semakin erat dan hangat. Banyak pertanyaan-pertanyaan terkait materi pelatihan yang terlontar dalam pertemuan informal ini. Kunjungan keliling kampong wisata juga kerap dilakukan pada saat kunjungan informal.

Puncak kegiatan pengmas dilakukan pada tanggal 8 Juli 2016. Tanggal tersebut dipilih berdasarkan kesepakatan antara tim pelaksana dari AMIK Indonesia dan tim mitra, dalam hal ini para komunitas pengelola Kampung Iboih. Selain itu tanggal tersebut bertepatan dengan hari Sabtu dirasa oleh pihak mitra sebagai waktu yang tepat dengan pertimbangan karena pada hari Sabtu tersebut adalah hari dimana Kampung Lawas biasanya kedatangan tamu dan pada hari tersebut tidak terlalu banyak pengunjung sehingga banyak anggota komunitas yang memiliki cukup waktu dan available untuk mengikuti kegiatan pelatihan.

Persiapan pelaksanaan kegiatan sangatlah diperhatikan. Persiapan yang bersifat tehnis seperti pembelian spanduk dan penggandaan copy materi dilakukan sejak dari Surabaya. Selain itu diperhatikan pula layar LCD dan materi power point serta lighting juga sangat diperhatikan. Hal 
ini penting karena jangan sampai acara terkendala hanya karena masalah tehnis dan efisien dan efektif.

Sementara itu snack dan nasi sebagai konsumsi juga dipersiapkan sebaik mungkin oleh tim pelaksana agar kegiatan benar-benar dapat terlaksana dan peserta juga nyaman dalam kegiatan (tidak merasa kehausan dan kelaparan). Pada pukul 08.00wib tim dari AMIK Indonesia sudah sampai di lokasi kegiatan. Setelah diterima oleh beberapa perangkat Kampung Iboih, maka tim pelaksana dan dibantu oleh beberapa masyarakat Desa segera menata meja dan kursi serta LCD di lokasi. Beberapa saat kemudian peserta mulai berduyun-duyun mendatangi lokasi. Banyak peserta undangan yang membawa tetangga atau temannya (di luar undangan yang tertulis). Banyaknya peserta yang melebihi undangan menunjukkan antusiasme peserta terhadap kegiatan pelatihan serta keingintahuan yang besar dari peserta untuk mengetahui dan menambah wawasan dan skill tentang bagaimana membuat paket wisata dan memberikan pelayanan kepada tamu.

Berdasarkan pertimbangan tersebut maka peserta di luar undangan tetap diperbolehkan mengikuti kegiatan pelatihan. Lebih-lebih ketika salah seorang pengurus Kampung Iboih mengatakan bahwa kegiatan pelatihan sebagaimana yang dilakukan oleh Tim AMIK Indonesia merupakan kegiatan yang sangat penting dan langka dilakukan bagi mereka sehingga pengurus meminta anggota komunitas untuk datang ke acara pelatihan.

Kegiatan inti yakni pemaparan materi dilakukan dalam tiga sesi, sebagai berikut:

a. Sesi pertama adalah presentasi tentang pentingnya manajemen destinasi wisata

b. Sesi kedua adalah pemaparan tentang standarisasi pelayanan SDM melalui pelayanan prima

c. Sesi ketiga adalah pemaparan tentang pariwisata dan paket wisata

Dalam sesi penjelasan materi ini dilakukan secara dialogis atau dua arah. Apabila ada perserta yang belum paham dan ingin menanyakan seputar materi atau dalam hal mengelola suatu objek wisata dapat langsung menanyakan kepada pematerinya. Dengan metode ini maka pesertapun terlihat bersemangat mengikuti jalannya acara karena terlibat dalam dialog- dialog di sesi penjelasan materi-materi tersebut.

Inti dari pengabdian desa ini yaitu untuk mempraktikan bagaimana cara mengelola dan melayani pengunjung yang datang dengan benar sesuai yaitu melayani dengan standart pelayanan yang prima. Dalan kegiatan ini dilakukan penjelasan materi dengan orang yang telah berpengalaman dalam dunia pariwisata, pemateri yang juga sebagai dosen mulai memberikan materi dimulai dari bagaimana ciri-ciri sesuatu bisa dijadikan sebagai objek wisata, diantaranya yaitu ada sebuah tempat dan ada yang di tonjolkan dari tempat tersebut. Di sini di Kampung Iboih sudah menggambarkan sesuatu yang bisa untuk mencipkan suatu objek wisata, yaitu tempat, yang bertempatkan di jalan Iboih tersebut, lalu sesuatu yang ditonjolkan yaitu kampung yang memiliki sejarah atau history pada jaman dahulu sebelum Indonesia merdeka, bangunan dalam Gang Iboih tersebut memang sudah banyak yang direnovasi oleh pemiliknya, mungkin bertujuan untuk mempercantik rumahnya, namun beberapa rumah masih nampak bangunan yang sengaja memang di biarkan seperti bangunan sejak dahulu, lalu memang ada bangunan yang sengaja di kosongkan dan tidak berpenghuni dan bangunan tersebut masih berdiri dan belum pernah sekalipun dilakukan renovasi, jadi intinya bangunan tersebut memangbangunan sejak dulu kala.

Sesi kedua, yaitu dijelaskan oleh dosen dari D3 Vokasi Pariwisata, menjelaskan bagaimana suatu memberikan suatu pelayanan yang prima kepada pengunjung yang datang, pelayanan sendiri adalah proses pemenuhan kebutuhan melalui aktivitas orang lain secara langsung. pengertian pelayanan prima adalah salah satu usaha yang dilakukan untuk melayani pembeli (pelanggan) dengan sebaik-baiknya, sehingga dapat memberikan kepuasan kepada pelanggan dan memenuhi kebutuhan serta keinginan pelanggan, baik yang berupa produk barang atau jasa. Dalam melayani pengunjung yang datang tidak hanya sekedar memberi sapa kepada tamu yang baru saja datang, namun harus memperhatikan sepenuh hati kebutuhan dari pengunjung tersebut

\subsection{Masyarakat Sasaran}

Adapun ruang lingkup utama dari kegiatan pengabdian kepada masyarakat ini adalah untuk memberikan pengetahuan dan meningkatkan kemampuan penglola dan warga Kampung Wisata Iboih Kota Sabang dalam mengelola destinasi wisata. Kelompok sasaran pengabdian ini adalah : 
a) Anggota Kelompok Wisata

b) Anggota Kelompok Pemuda Desa Iboih

c) Jumlah peserta dalam pelatihan ini berjumlah 20 orang. Peserta pelatihan diharapkan berasal dari kalangan Kelompok Tani dan Pemuda Desa Iboih

\section{Tinjauan Hasil yang dicapai}

Tinjauan dari hasil kegiatan ini adalah masyarakat khususnya pengurus maupun warga sekitar Kampung Iboih keluarahan Sukakarya Kota Sabang masih perlu adanya sosialisasi dan penyuluhan bagaimana mengelola suatu objek wisata. Oleh karena itu mereka masih membutuhkan informasi dan wawasan yang lebih untuk mengelolah suatu objek wisata dan melayani pengujung dengan pelayanan prima. Oleh karenanya, kegiatan penyuluhan mengelolah objek wisata dan pelayanan prima ini penting bagi masyarakat setempat untuk dilakukan agar pengetahuan dan skill untuk mengelola objek wisata ini menjadi meningkat dalam segi menjual dan mendatangkan pengunjung yang lebih dari sebelumnya

\section{Daftar Pustaka}

[1] Himawan, H., 2015, July. E-tourism: Antara konsep dan implementasi dalam mendukung industri pariwisata Indonesia. In Seminar Nasional Informatika (SEMNASIF) (Vol. 1, No. 5).

[2] Ahyuni, A. and Sri, M., 2015. Minat Wisatawan Asing Berkunjung ke Objek Wisata di Wilayah Bagian Selatan Propinsi Sumatera Barat. Jurnal Geografi, 4(2), pp.200-212.

[3] Hermawan, W. and Wardhana, A., 2016. Analisis Faktor-Faktor yang Mempengaruhi Kunjungan Wisatawan Mancanegara ke Indonesia. QE Journal, 5(1).

[4] Statistik, B.P., 2012. Survei demografi dan kesehatan Indonesia 2012. Jakarta: Badan Pusat Statistik.

[5] Krstic, B., Jovanovic, S., Jankovic-Milic, V. and Stanisic, T., 2016. Examination of travel and tourism competitiveness contribution to national economy competitiveness of sub-Saharan Africa countries. Development Southern Africa, 33(4), pp.470-485.

[6] Pariwisata, K. and Indonesia, E.K.R., 2012. Rencana Strategis 2012-2014. Jakarta: Kementerian Pariwisata dan Ekonomi Kreatif Republik Indonesia.

[7] Reindrawati, D.Y., 2020. PELATIHAN DAN PENDAMPINGAN PENGELOLAAN KAMPUNG WISATA LAWAS MASPATI SEBAGAI DESTINASI UNGGULAN BARU SURABAYA. ABDI KAMI: Jurnal Pengabdian Kepada Masyarakat, 3(1), pp.001-019.

[8] Wibowo, L.A. and Yuniawati, Y., 2007. The Influence of Tourist Product Attribute and Trust to Tourist Satisfaction and Loyalty A Study of Mini Vacation in Bandung. Ringkasan Hasil Penelitian Dosen.

[9] Widyaningsih, H., 2018. Upaya Peningkatan Profesionalisme Karyawan Untuk Meningkatkan Kualitas Pelayanan Karyawan Abadi Hotel Jogja. Khasanah Ilmu-Jurnal Pariwisata Dan Budaya, 9(1).

[10] Musanto, T., 2004. Faktor-faktor kepuasan pelanggan dan loyalitas pelanggan: Studi kasus pada CV. Sarana Media Advertising Surabaya. Jurnal Manajemen dan Kewirausahaan, 6(2), pp.123136. 
[11] RIZAL, S. and WALI, M., 2019. The Effect of Leadership Style, Compensation and Organizational Commitment to Working Satisfaction of Aceh Social Service Employees. Editorial Board, p.797.

[12] Rizal, S. and Wali, M., 2013. Dimensi Kesadaran Merek dan Keputusan Konsumen Memilih Hermes Palace Hotel di Kota Banda Aceh. Jurnal Ekonomi Manajemen dan Bisnis (EMBis), 1(1), pp.27-41.

[13] Heffy, M., 2009. Reformasi Manajemen Pelayanan Publik Menuju Good Governance. Jurnal Borneo Administrator, 5(2).

[14] Amri, K., 2013. Faktor-Faktor Yang Mempengaruhi Loyalitas Konsumen Surat Kabar Harian Serambi Indonesia di Kota Banda Aceh. Jurnal Ekonomi Manajemen dan Bisnis, 1(2), pp.229242.

[15] Audina, M., 2018. Pelayanan Prima dalam Menangani Paspor Hilang dan Rusak pada Kantor Imigrasi Kelas I Polonia Medan.

[16] Nurlia, N., 2018. Strategi Pelayanan dengan Konsep Service Excellent. Meraja journal, 1(2), pp.17-30.

[17] Audina, M., 2018. Pelayanan Prima dalam Menangani Paspor Hilang dan Rusak pada Kantor Imigrasi Kelas I Polonia Medan.

[18] Barata, A.A., 2003. Dasar-dasar pelayanan prima. Elex Media Komputindo.

[19] Nurlia, N., 2018. Strategi Pelayanan dengan Konsep Service Excellent. Meraja journal, 1(2), pp.17-30.

[20] Maryam, N.S., 2016. Mewujudkan good governance melalui pelayanan publik. Jurnal Ilmu Politik dan Komunikasi: Politeknik Kridatama Bandung.

[21] Singgih, E.M. and Bawono, I.R., 2010. Pengaruh Independensi, Pengalaman, Due Professional Care dan Akuntabilitas Terhadap Kualitas Audit. Simposium Nasional Akuntansi XIII, pp.121. 